ARTICLE

httpst//doi.org/10.1038/s41467-021-25198-y

\title{
Biomimetic approach to the catalytic enantioselective synthesis of tetracyclic isochroman
}

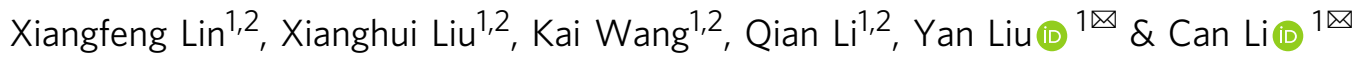

Polyketide oligomers containing the structure of tetracyclic isochroman comprise a large class of natural products with diverse activity. However, a general and stereoselective method towards the rapid construction of this structure remains challenging due to the inherent instability and complex stereochemistry of polyketide. By mimicking the biosynthetic pathway of this structurally diverse set of natural products, we herein develop an asymmetric hetero-Diels-Alder reaction of in-situ generated isochromene and ortho-quinonemethide. A broad range of tetracyclic isochroman frameworks are prepared in good yields and excellent stereoinduction (up to $95 \%$ ee) from readily available $\alpha$-propargyl benzyl alcohols and 2(hydroxylmethyl) phenols under mild conditions. This direct enantioselective cascade reaction is achieved by a $\mathrm{Au}(\mathrm{I}) / \mathrm{chiral} \mathrm{Sc}(\mathrm{III})$ bimetallic catalytic system. Experimental studies indicate that the key hetero-Diels-Alder reaction involves a stepwise pathway, and the steric hindrance between in-situ generated isochromene and $t$-Bu group of $\mathrm{Sc}(\mathrm{III}) / N, N^{\prime}$-dioxide complex is responsible for the enantioselectivity in the hetero-Diels-Alder reaction step.

\footnotetext{
${ }^{1}$ State Key Laboratory of Catalysis, Dalian Institute of Chemical Physics, Chinese Academy of Sciences, Dalian, China. ${ }^{2}$ University of Chinese Academy of

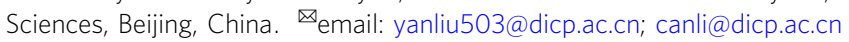


T etracyclic isochromans, a type of polyketide oligomers ${ }^{1-3}$, are ubiquitously present in numerous natural products and bioactive molecules. For instance, Chaetophenol $\mathbf{D}$ was induced from chemically mediated epigenetic manipulation of fungal gene expression, exhibiting excellent anti-adenovirus activity ${ }^{4}$. Indigotide $\mathbf{C}$ and its isomer were biosynthesized by cultivation of Cordyceps indigotica, an entomopathogenic fungus, in the presence of suberoyl bis-hydroxamic acid, exhibiting good antibacterial activity $^{5}$ (see Fig. 1a). Thus, the development of a general and stereoselective method towards a rapid construction is highly desirable. However, to our knowledge, such an effient methodology has not yet been established so far ${ }^{6}$, probably due to the inherent instability of tetracyclic isochroman polyketide and the difficulties in controlling the complex stereochemistry.

As an important intermidiate, ortho-quinone methide (o-QM) has caught much attention in the field of asymmetric catalysis $^{7-26}$. Moreover, this highly reactive specie was proposed to be the diene intermidiate in the biosynthesis of several polyketide natural products via hetero-Diels-Alder (HDA) reaction. Asai and Oshima speculated a biosynthetic route of Indigotide C involving isochromene and $o$-QM intermidiates ${ }^{5}$. The same group developed a biosynthetic approach for the construction of a pseudo-natural fungal polyketide $\mathbf{A}$ by using $\mathbf{1}$ as substrate in $2015^{27}$ (see Fig. 1b). The key of this method also lies in a HDA reaction of isochromene and $o-\mathrm{QM}$ which were heterologously biosynthesized by introducing the NR-PKS-encoding gene into Aspergillus oryzae. Inspired by this possible biosynthetic route of poliketide oligomer, we decided to exploit an artificial asymmetric catalytic system from the similar intermediates to build this complex structure. To the best of our knowledge, it is worth noting that there has been no report of biomimetic asymmetric catalytic HDA reaction involving $o$-QMs intermediates. The development of biomimetic HDA route for the synthesis of core structure of these natural products is of great significance to not only understand biosynthetic HDA reactions involving $o$-QM intermediates, but also expand the limitation of substrates catalyzed by Diels-Alderase enzymes ${ }^{28-34}$. The establishment of the enantioselective biomimetic polyketide oligomer synthesis requires the methods for the generation of isochromene and $o$ QM intermidiates and a catalyst capable of promoting the stereoselective $\mathrm{HDA}$ reaction. It is known that $\mathrm{Au}(\mathrm{I})$ complexes have been used in the cascade reactions $s^{35-39}$ and could promote the intramolecular cyclization of benzyl alcohol-functionalized alkynes to isochromene intermediate ${ }^{40,41}$, and the $o$-QM intermidiate could be generated from the proper precursor in the presence of either acid or base.

Recently, Au/Lewis acid bimetallic catalysis has been exploited to be a strategy to construct aminals and ketals via 5-exo-dig cyclization of alkynyl amides or alcohols and relay cycloaddition reactions with electrophiles ${ }^{42-49}$. Moreover, Feng's group developed the first highly efficient asymmetric bimetallic $\mathrm{Au}(\mathrm{I}) / \mathrm{chiral}$ $\mathrm{Ni}$ (II) catalytic cascade reaction of $\alpha, \beta$-unsaturated $\gamma$-keto esters with alkynyl amides and alcohols for the synthesis of spiroketals and spiroaminals in $2016^{50}$. Kang and coworkers realized the same reaction by employing a $\mathrm{Au}(\mathrm{I}) / \mathrm{chiral} \mathrm{Rh}(\mathrm{III})$ catalytic system two years later ${ }^{51}$. Inspired by these elegant works, we envisioned that a combination of a $\mathrm{Au}(\mathrm{I})$ catalyst and a chiral lewis acid catalyst might enable the HDA reaction of in-situ generated isochromene and $o$-QM to deliver the optically active tetracyclic isochromans, despite of that the acceptors of reported asymmetric $\mathrm{Au} /$ Lewis acid bimetallic catalysis were limited to $\alpha, \beta$-unsaturated $\gamma$-keto esters, and the most of known asymmetric cascade reactions of alkynyl alcohols delivered spiro products rather than fused products ${ }^{50,52-61}$.

In this work, we found a highly efficient $\mathrm{Au}(\mathrm{I}) / \mathrm{chiral} \mathrm{Sc}(\mathrm{III})$ bimetallic catalytic system which could achieve asymmetric HDA reaction of in-situ generated isochromene and ortho-quinonemethide $(o-\mathrm{QM})$, and provided a diversity of tetracyclic isochromans in moderate to high yields and with high levels of diastereoselectivities and enantioselectivities (up to 95\% ee) (see Fig. 1c).

(a) Natural polyketides containing tetracyclic isochromans.

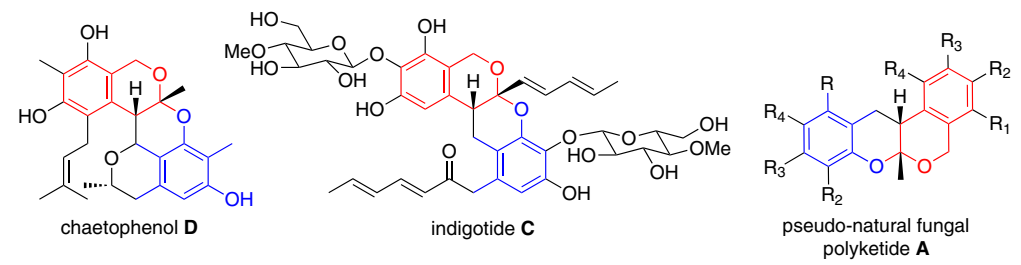

(b) The possible biosynthetic route of tetracyclic isochroman polyketide catalyzed by NR-PKS.

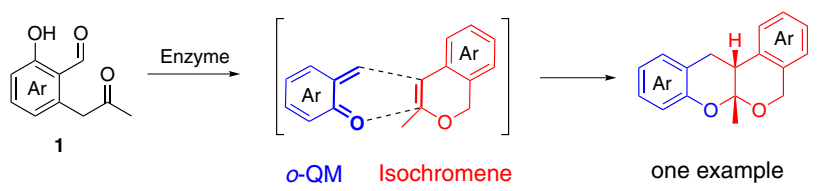

(c) This work:

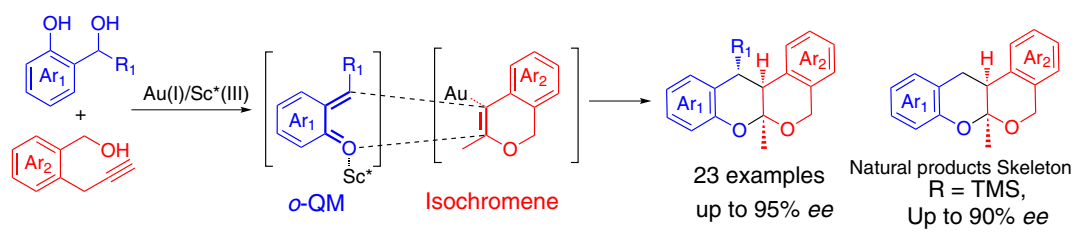

Fig. 1 Background of tetracyclic isochromans and biomimetic design. a Natural polyketides containing tetracyclic isochromans. $\mathbf{b}$ The possible biosynthetic route of tetracyclic isochroman polyketide catalyzed by NR-PKS. c The bioinspired Au/Sc*catalyzed HDA reaction. 


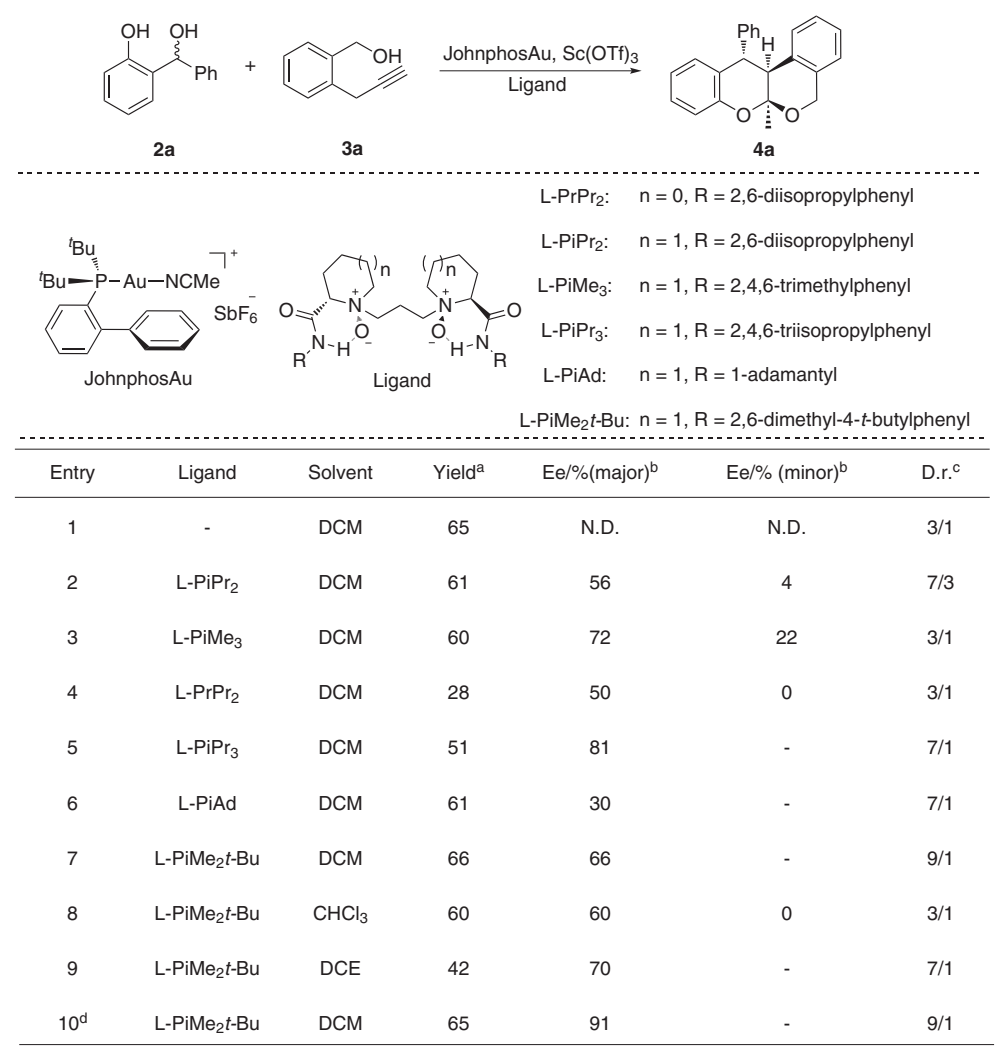

Fig. 2 Optimization of the reaction. All reactions were carried out on a $0.1 \mathrm{mmol}$ scale with 1 eq precursor of o-QMs $\mathbf{2 a}$, 1.2 eq $\mathbf{3 a}$, $10 \mathrm{~mol} \%$ of Sc(OTf) $)_{3}, 11$ mol\% of ligand and $5 \mathrm{~mol} \%$ of JohnphosAu in DCM $(1 \mathrm{~mL})$ at room temperature. alsolated yield. betermined by chiral HPLC. ${ }^{\circ}$ Determined by by crude ${ }^{1} \mathrm{H}-\mathrm{NMR}$. dReaction temperature: $6^{\circ} \mathrm{C}$.

\section{Results and discussion}

Studies commenced by screening effective precursors of $o$-QMs and the corresponding catalysts. We selected $\alpha$-propargyl benzyl alcohol 3a as model substrate and JohnphosAu as the catalyst to generate isochromene intermidiate. 2-(Hydroxylmethyl) phenol 2a was chosen as the precursor of $o$-QM. Representative Lewis acids and Brønsted acids were investigated in the presence of 1.2 equivalent $\mathbf{3 a}$ and JohnphosAu catalyst (see the Supporting Information, Table $\mathrm{S} 2)$. $\mathrm{Sc}(\mathrm{OTf})_{3}$ was found to be the only efficient catalyst for this reaction, affording the HDA product $\mathbf{4 a}$ in $65 \%$ yield with $3 / 1$ d.r. (Fig. 2, entry 1 ). Subsequently, a series of other noble metal complexes such as $\mathrm{Pd}(\mathrm{II}), \mathrm{Ag}(\mathrm{I})$ and $\mathrm{Au}(\mathrm{I})$ complex were evaluated to generate isochromene intermidiate, but only (acetonitrile)Au-complex delivered the desire HDA products in good yield and no product was obtained by in-situ formed Au-complex (see the Supporting Information, table S2). Next, the screening of different types of chiral ligands for the purpose of achieving the asymmetric version of this reaction suggested that Feng ligands ( $N, N$-dioxide) showed unique activities in the asymmetric HDA reaction of in-situ generated isochromenes and $o$-QMs (Fig. 2, entries 2-7). The use of $(S)$ proline derived $\mathrm{L}-\mathrm{PrPr}_{2}$ resulted in lower diastereoselectivities and enantioselectivities than (S)-piperidine derived $\mathrm{L}-\mathrm{PiPr}_{2}$ (Fig. 2, entry 2 VS entry 4). More sterically hindered substituents at the para positions of aniline were beneficial to improve both diastereoselectivities and ee values (Fig. 2, entries 5 and 7 VS entries 2 and 3) and aniline derived $\mathrm{L}-\mathrm{PiMe}_{2} t$-Bu resulted in higher ee values than amantadine derived L-PiAd (Fig. 2, entry 6 $V S$ entry 7). The solvent screening suggested that the catalytic reactions were available in chlorinated solvents and DCM gave the best yield and selectivity (Fig. 2, entries 7-9). Notably, after cooling to $6^{\circ} \mathrm{C}$, the ee value of the HDA product $4 \mathbf{a}$ was increased to $91 \%$ with little drop of yield (Fig. 2, entry 10). Therefore, the optimized conditions involved the use of $\mathrm{L}-\mathrm{PiMe}_{2} t-\mathrm{Bu} / \mathrm{Sc}(\mathrm{OTf})_{3}$ and JohnphosAu as catalysts in DCM at $6{ }^{\circ} \mathrm{C}$ (Fig. 2, entry 10).

Under optimized reaction conditions, the substrates scope of the reaction was examined. A series of aryl-substituted orthohydroxybenzyl alcohols 2a-i were tested with $\mathbf{3 a}$ as model $\alpha$ propargyl benzyl alcohol (Fig. 3). Pleasingly, either electrondonating or electron-withdrawing substituents at the para- or meta-position of the benzene ring $(2 \mathbf{a}-\mathbf{g})$ were well tolerated, affording the corresponding poliketide oligomers in moderate yields and with good to excellent diastereoselectivities and enantioselectivities. In particular, the reactions of $o$-QMs with 2-naphthyl and 4-biphenyl substituents successfully afforded the desired products $(4 \mathbf{h}, \mathbf{i})$ in $76 \%$ and $60 \%$ yield with $90 \%$ and $84 \%$ ee respectively. However, ortho-substituted aryl groups have an extremely detrimental effect on the reactivity of this reaction probably due to the steric hinder effect. On the other hand, substituents at the quinone methide fragment were tolerated as well, and the corresponding adducts $\mathbf{4 j - 0}$ were obtained in good to excellent enantioselectivities $(81-89 \%$ ee $)$. Notably, alkylsubstituted $o$-QMs were also demonstrated to be acceptors amenable to the reaction protocol, giving rise to the corresponding products $\mathbf{4 p - q}$ with enantioselectivities up to $75 \%$ ee. However, a variety of ortho-aminobenzyl alcohols could not afford the desired product probably due to the low reactivity of $a z a$-o-quinone methide. The absolute configuration of $\mathbf{4 l}$ was determined to be $(S$, $S, S$ ) on the basis of single crystal X-ray diffraction analysis.

Subsequently, we turned our attention to the substrates scope of $\alpha$-propynyl benzyl alcohols by using $o$-QM precursor $\mathbf{2} \mathbf{h}$ as substrate. As shown in Fig. 4, a wide range of $\alpha$-propynyl benzyl alcohols $3 \mathbf{b}$-i bearing different substituted aryl groups reacted with $\mathbf{2} \mathbf{h}$ quite well to form the corresponding poliketide 


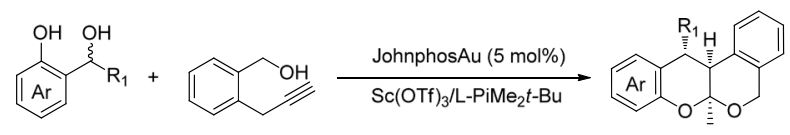

2

3a

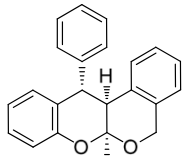

$4 a$

$65 \%$ yield, $9: 1$ d.r.,

$91 \%$ ee.

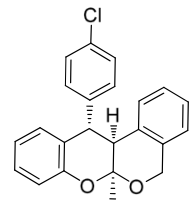

$4 \mathbf{f}$

$61 \%$ yield, $10: 1$ d.r. $94 \%$ ee.

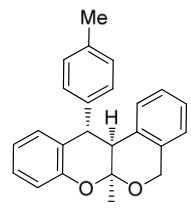

4b

$65 \%$ yield, $14: 1$ d.r.

$88 \%$ ee.

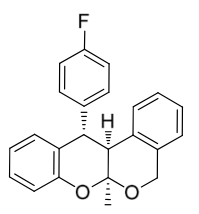

$\mathbf{4 g}$

$52 \%$ yield, $17: 1$ d.r., $91 \%$ ee.

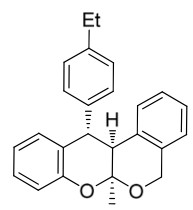

$4 c$

$68 \%$ yield $14: 1$ d.r.

$90 \%$ ee

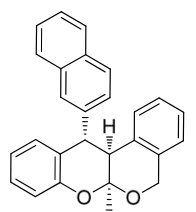

$4 \mathrm{~h}$

$76 \%$ yield, $11: 1$ d.r. $90 \%$ ee.

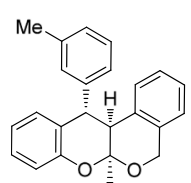

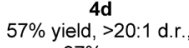

$87 \%$ ee.

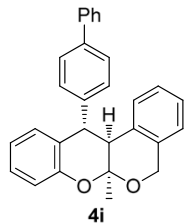

$60 \%$ yield, $13: 1 \mathrm{~d} . r$ $84 \%$ ee.

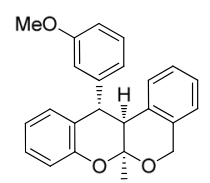

$4 e$

$63 \%$ yield, $6: 1 \mathrm{~d} . \mathrm{r}$ $89 \%$ ee.
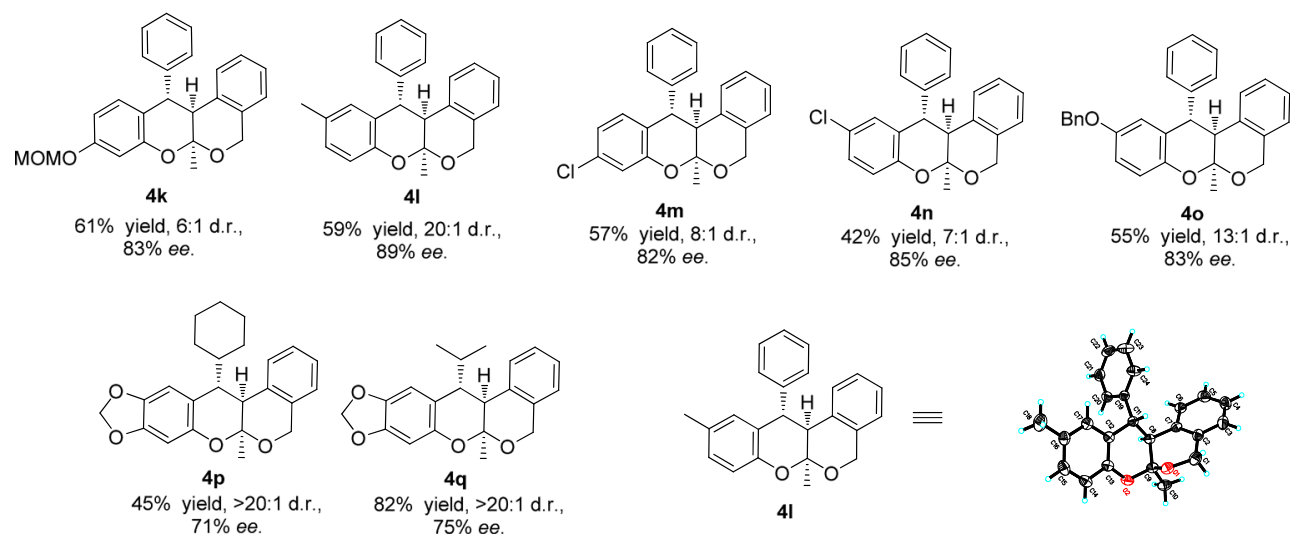

$71 \%$ ee .

$75 \%$ ee

41

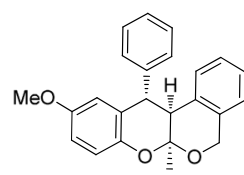

4j

$57 \%$ yield, $17: 1$ d.r.,

$87 \%$ ee.

Fig. 3 Substrates scope of o-QMs. Unless otherwise noted, all reactions were carried out on a 0.2 mmol scale with 1.0 eq precursor of o-QMs 2, 1.2 eq 3a, $10 \mathrm{~mol} \%$ of $\mathrm{Sc}(\mathrm{OTf})_{3}, 11 \mathrm{~mol} \%$ of L-PiMe 2 -Bu and $5 \mathrm{~mol} \%$ of JohnphosAu in DCM (2.0 mL) under $6{ }^{\circ} \mathrm{C}$. Isolated yield for major diastereomer. ee was determined by chiral HPLC. D.r. was detected by crude ${ }^{1} \mathrm{H}-\mathrm{NMR}$.

oligomers $4 \mathbf{r}-\mathbf{4 y}$ in good to moderate yields (43-72\%) with excellent ee values (89-95\%). In general, electron-donating groups furnished the poliketides $\mathbf{4 r}$ and $\mathbf{4 s}$ in higher yields than those with electron-withdrawing substituents $\mathbf{4 t}-\mathbf{y}$, albeit in similarly high ee values. Cbz-protected $\alpha$-propargyl benzyl amine $\mathbf{3 j}$ as well as various alkyl benzyl alcohol derivatives $3 \mathbf{k}-\mathbf{q}$ was investigated in this cascade reaction under the optimized reaction conditions. $\mathbf{3 j}$ reacted with $\mathbf{2 h}$ quite well to form the corresponding N-aza poliketide oligomer 5a in 63\% yield, 1.5:1 d.r with $22 \%$ ee for major diastereoisomer and $15 \%$ ee for minor diastereoisomer. The reactions between $\mathbf{2 h}$ and $\alpha$-ethynyl benzyl alcohols 3k-1 were carried out with L-PiAd as ligand and chiral spiro products $5 \mathbf{b}-\mathbf{c}$ were isolated in $72-76 \%$ yield and $52-55 \%$ ee . 2-(Propynyl)phenol $\mathbf{3 m}$ was also tolerated as well under the standard reaction condition and gave the corresponding chiral spiro product $5 \mathbf{d}$ in $31 \%$ yield with $37 \%$ ee. Moreover, alkyl benzyl alcohol $3 \mathbf{o}$ reacted with $2 \mathbf{h}$ to form the product $5 \mathbf{f}$ by $1,4-$ addition without annulation in 8 membered ring system likely due to the ring strain. It is worth mentioning that the reaction between $\mathbf{3 n}$ and $\mathbf{2 h}$ was messy toward 7 membered ring system and poliketide oligomer $5 \mathbf{e}$ was isolated in $14 \%$ yield with $0 \% e e$. Internal alkynes $\mathbf{3} \mathbf{p}-\mathbf{q}$ were also demonstrated to be reactants amenable to the reaction protocol, giving rise to the corresponding products 5 g-h in $39-41 \%$ yield with $53-55 \%$ ee. Hexynols $3 \mathbf{s - t}$ are unavailable substrates in this catalytic system. However, pentynol derivative $\mathbf{3 r}$ reacted quite well with $\mathbf{2 h}$ to form the chiral spiro product $5 \mathbf{i}$ in $52 \%$ yield with $66 \%$ ee.

To evaluate the synthetic potential of this protocol, the cascade reaction of $\mathbf{2 h}$ and $\mathbf{3 a}$ was carried out on a gram scale under optimized reaction conditions with $\mathrm{Au}(\mathrm{I}) / N, N^{\prime}$-dioxide-Sc(III) complex. The corresponding product, tetracyclic isochroman poliketide oligomer $\mathbf{4 h}$, could be obtained with $52 \%$ yield, 9:1 d.r. and $90 \%$ ee (Fig. 5a). In addition, derivatizations of product 4 were performed without loss of enantiopurity of the functionalized products. For example, the controllable selective cleavages of $\mathrm{C}-\mathrm{O}$ bonds in poliketide $\mathbf{4 d}$ were carried out without any deterioration of enantiopurity (Fig. 5b). In the presence of strong Lewis acid $\mathrm{BF}_{3} \bullet \mathrm{OEt}, \mathbf{4 d}$ was readily cleaved to the corresponding oxonium ion to furnish bioactive compound $\mathbf{6}$ which was reported to be an estrogen receptor degrader for treatment of ER + breast cancers with good yield and complete diastereocontrol (Fig. 5b, black part). If $\mathrm{TiCl}_{4}$ was used as strong Lewis acid instead of $\mathrm{BF}_{3} \cdot \mathrm{OEt}$, $4 \mathbf{d}$ was readily transformed to another oxonium ion and phenol 7 was obtained (Fig. 5b, blue part). Considering the 


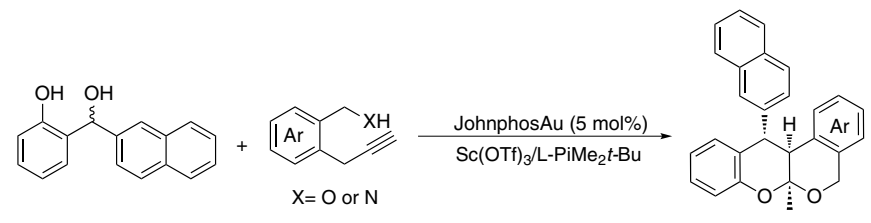

2h

3b-

4
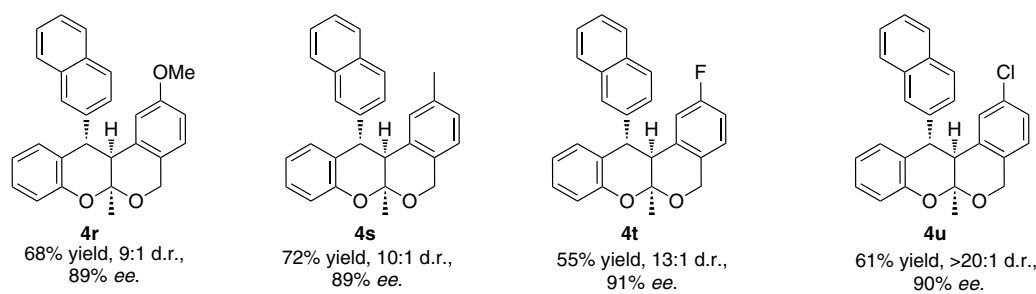

$4 \mathrm{u}$

$61 \%$ yield, $>20: 1$ d.r.,<smiles>C[C@]12Oc3ccccc3[C@@H](c3ccc4ccccc4c3)[C@@H]1OCc1cc(Cl)ccc12</smiles>

$4 \mathrm{v}$

$55 \%$ yield, $3: 1$ d.r., $91 \%$ ee.

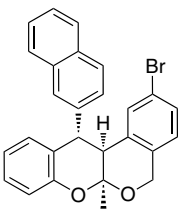

$4 \mathbf{w}$

$62 \%$ yield, $11: 1$ d.r.,
$94 \%$ ee.

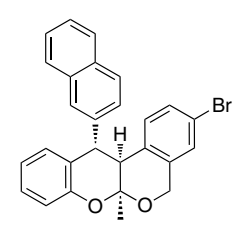

$4 \mathbf{x}$ $58 \%$ yield, $4: 1$ d.r.,

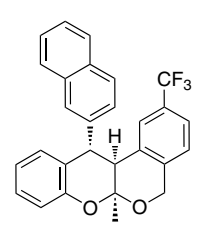

$4 y$

$43 \%$ yield, $5: 1$ d.r.,

$95 \%$ ee.

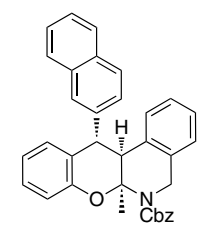

$5 a$

$63 \%$ yield, $1.5: 1$ d.r.,

$22 \%$ ee for major diastereoisomer $15 \%$ ee for minor diastereoisomer

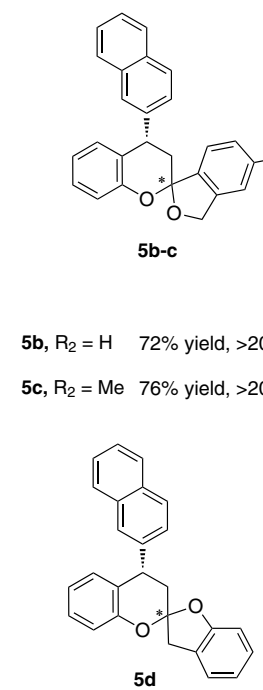

$5 d$

$31 \%$ yield, >20:1 d.r., $37 \%$ ee.

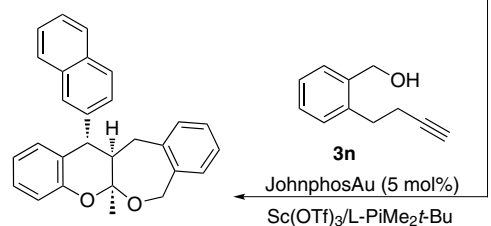

$5 e$

$14 \%$ yield, >20:1 d.r., $0 \%$ ee.<smiles>[R]c1ccc(C#C)c(CO)c1</smiles>

3k-I

JohnphosAu (5 mol\%)

$\mathrm{Sc}(\mathrm{OTf})_{3} / \mathrm{L}-\mathrm{PiAd}^{\mathrm{a}}$

(2) 
(a)

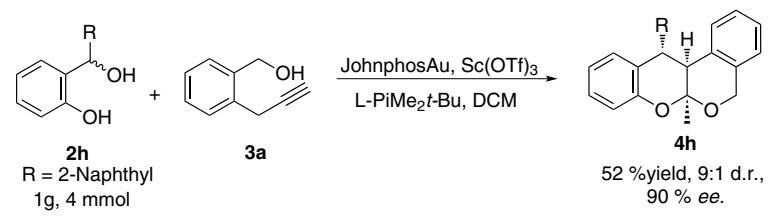

(b)
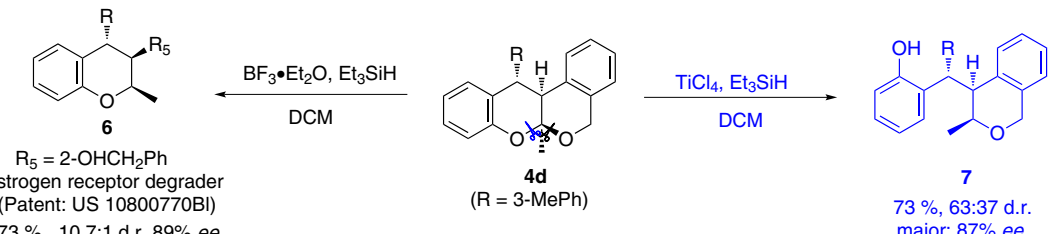

(Patent: US 10800770B

major: $87 \%$ ee.
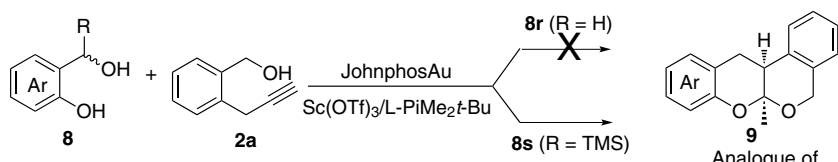

pseudo-natural fungal polyketide $\mathrm{A}$

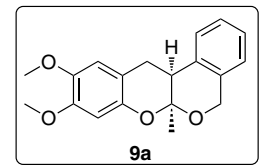

$39 \%$ yield, $>20: 1$ d.r. $90 \%$ ee.

Fig. 5 The gram scale experiment and transformations of product 4. a The gram scale experiment. $\mathbf{b}$ Reduction of product $\mathbf{4 d}$. c Synthesis of analogue of pseudo-natural fungal polyketide $\mathbf{A}$.

phenols 2 and $\alpha$-propargyl benzyl alcohols 3 with the catalysis of $\mathrm{Sc}(\mathrm{III}) / \mathrm{Au}(\mathrm{I})$, we endeavored to determine whether the HDA reaction of in-situ generated isochromene and ortho-quinonemethide proceeds via a concerted or stepwise pathway. To address this question, we investigated the carbon isotope effects for the $[4+2]$ reaction between $\mathbf{2 b}$ and $\mathbf{3 a}$ using Singleton's method at natural abundance ${ }^{62,63}$. When the reaction was stopped at $71 \%$ conversion, the ${ }^{13} \mathrm{C}$ ratio of each carbon in the recovered 3-methyl-1H-isochromene $\mathbf{1 0}$ to the same carbon in virgin 10 was measured using quantitative ${ }^{13} \mathrm{C}$ NMR. As shown in Fig. 6, the only appreciable carbon isotope effect was observed at the 4-C-position of 10, thus indicating that the HDA cycloaddition might proceed through a stepwise mechanism to form adducts.

In order to investigate the role of the Au-complex in this enantioselective cascade reaction, we investigated the hetero-DielsAlder reaction between $o$-QMs precursor $\mathbf{2 b}$ and 3-methyl- $1 \mathrm{H}$ isochromene $\mathbf{1 0}$ with or without the participation of Au-complex (Fig. 7, entry 2 and 3). Two catalytic reactions afforded the tetracyclic isochroman poliketide oligomer $\mathbf{4 b}$ in similar yield, d.r. and $e e$ values comparing to the cascade reaction between $\mathbf{2 b}$ and 3a (Fig. 7, entry 1), which suggests that $\mathbf{1 0}$ may be the real active intermediate in the $[4+2]$ cycloaddition and Au-complex may not participate in the control of the enantioselectivity.

Based on the reported X-ray structure of the $N, N^{\prime}$-dioxide $\mathrm{Sc}^{\mathrm{III}}$ complex ${ }^{64}$ and the absolute configuration of the product 4 as well as the results of control experiments, we proposed a catalytic model for the Au/Sc*atalyzed HDA reaction (Fig. 8). A complex with octahedral geometry as the transition state is formed by coordinating $\mathrm{L}-\mathrm{PiMe}{ }_{2} t$-Bu and $o$-QMs to $\mathrm{Sc}^{\mathrm{III}}$ center. The enol attack takes place from the less hindered $S i$ face of the $o$-QMs to form the first chiral center in the benzylic position of $o$-QM skeleton (Fig. 8, 1a VS 1b). Subsequent oxygen anion attack to oxonium ion affords the desired optical tetracyclic isochroman from $S i$ face, while the $R e$ face of the oxonium ion is shielded by the $N, N$ '-dioxide (Fig. 8, 1c VS 1d).

In summary, we designed and developed the first asymmetric HDA reaction of in-situ generated isochromene and $o$-QM based on insights from the biosynthetic pathway of polyketide oligomer

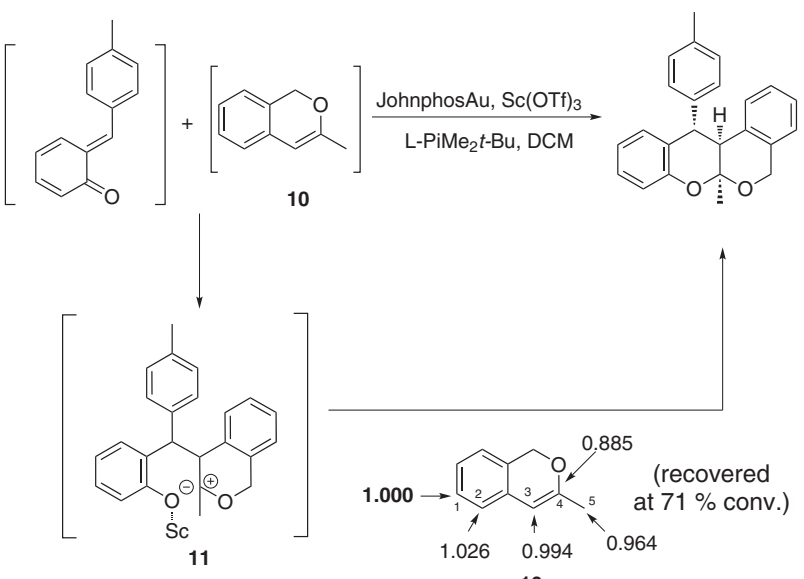

10

Fig. 6 Carbon isotope effects $\left(\mathbf{R} / \mathbf{R}_{\mathbf{0}}\right)$ calculated for $\mathbf{3 a}$. The carbon valued in bold was taken as the internal standard.

natural products. This direct enantioselective cascade reaction was achieved through a $\mathrm{Au}(\mathrm{I}) / \mathrm{Sc}$ (III) bimetallic catalytic strategy, affording a series of chiral tetracyclic isochromans from readily available $\alpha$-propargyl benzyl alcohols and 2-(hydroxylmethyl) phenols under mild conditions. Importantly, this work demonstrates the potential utility of biomimetic synthesis in the development of reaction and expanding the limitation of substrates comparing to biosynthesis expansion, which encourages us to explore biomimetic catalytic reactions in the future.

\section{Methods}

General experimental procedure of asymmetric cascade reaction. To a $10-\mathrm{mL}$ test-tube were sequentially added JohnphosAu $(0.010 \mathrm{mmol}, 7.7 \mathrm{mg}), \mathrm{Sc}(\mathrm{OTf})_{3}$ $(0.020 \mathrm{mmol}, 9.8 \mathrm{mg})$, L-PiMe 2 - $\mathrm{Bu}(0.022 \mathrm{mmol}, 14.4 \mathrm{mg})$ and $\mathrm{CH}_{2} \mathrm{Cl}_{2}(2.0 \mathrm{~mL})$ The mixture stirred for $15 \mathrm{~min} . \alpha$-Propargyl benzyl alcohol $3(0.3 \mathrm{mmol})$ and substrate $2(0.2 \mathrm{mmol})$ were added in turn to the solution at $6^{\circ} \mathrm{C}$. The reaction mixture was monitored by TLC. Upon completion, the residual was purified by silica gel flash chromatography (petroleum ether:ethyl acetate, 20:1) to afford the desired product 4 . The racemic examples were prepared by the catalysis of Sc $(\mathrm{OTf})_{3}$ in r.t. 


(Sc)

Fig. 7 Controlled experiments. Unless otherwise noted, all reactions were carried out on a $0.2 \mathrm{mmol}$ scale with 1 eq $\mathbf{2 b}, 1.2$ eq $\mathbf{3 a}$ or $\mathbf{1 0}, 10 \mathrm{~mol} \%$ of $\mathrm{Sc}$ $(\mathrm{OTf})_{3}, 11 \mathrm{~mol} \%$ of $\mathrm{L}-\mathrm{PiMe} \mathrm{e}_{2} \mathrm{Bu}$ and $5 \mathrm{~mol} \%$ of JohnphosAu in $\mathrm{DCM}(2.0 \mathrm{~mL})$ under $6{ }^{\circ} \mathrm{C}$.

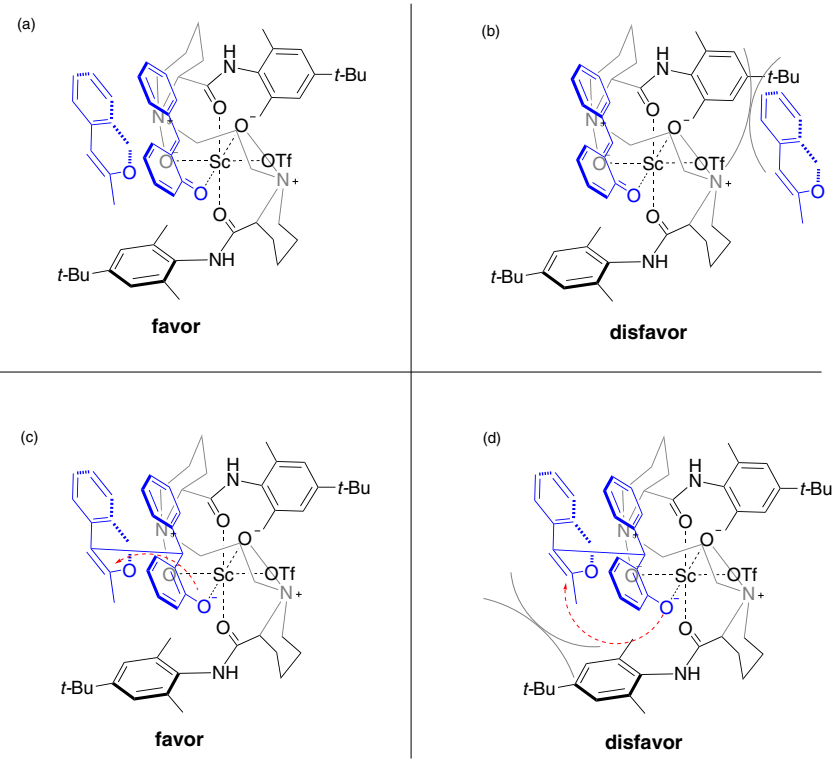

Fig. 8 Proposed stereochemical models. a Favor transition state of first step. $\mathbf{b}$ Disfavor transition state of first step. c Favor transition state of second step. d Disfavor transition state of second step.

Experimental procedure for synthesis of 6. Under Ar atmosphere, to a $10-\mathrm{mL}$ test-tube were sequentially added $\mathbf{4 d}(0.4 \mathrm{mmol}, 136.8 \mathrm{mg})(89 \% e e), \mathrm{CH}_{2} \mathrm{Cl}_{2}(2.0$ $\mathrm{mL}), \mathrm{Et}_{3} \mathrm{SiH}(0.4 \mathrm{mmol}, 46.4 \mathrm{mg})$ and $\mathrm{BF}_{3} \cdot \mathrm{Et}_{2} \mathrm{O}(0.2 \mathrm{~mL})$ in $0{ }^{\circ} \mathrm{C}$. Upon completion $(2 \mathrm{~h})$ the residual was purified by silica gel flash chromatography (petroleum ether: ethyl acetate, 5:1) to afford the desired product 6 .

Experimental procedure for synthesis of 7. Under Ar atmosphere, to a 10-mL test-tube were sequentially added $4 \mathbf{d}(0.2 \mathrm{mmol}, 68.4 \mathrm{mg})(89 \% e e), \mathrm{CH}_{2} \mathrm{Cl}_{2}(2.0$ $\mathrm{mL}), \mathrm{Et}_{3} \mathrm{SiH}(0.2 \mathrm{mmol}, 23.2 \mathrm{mg})$ and $\mathrm{TiCl}_{4}(0.1 \mathrm{~mL})$ in $0^{\circ} \mathrm{C}$. Upon completion $(2$ h) the residual was purified by silica gel flash chromatography (petroleum ether: ethyl acetate, 5:1) to afford the desired product 7 .

\section{Data availability}

Crystallographic data have been deposited in the Cambridge Crystallographic Data. Center under accession number CCDC: 2036557. These data can be obtained free of charge from The Cambridge Crystallographic Data Centre via.

Received: 14 January 2021; Accepted: 22 July 2021;

Published online: 16 August 2021

\section{References}

1. Sudek, S. et al. Identification of the putative bryostatin polyketide synthase Gene cluster from "Candidatus Endobugula sertula", the uncultivated microbial symbiont of the marine bryozoan bugula neritina. J. Nat. Prod. 70, 67-74 (2007).

2. Hang, L., Liu, N. \& Tang, Y. Coordinated and iterative enzyme catalysis in fungal polyketide biosynthesis. ACS Catal. 6, 5935-5945 (2016).

3. Nivina, A., Yuet, K. P., Hsu, J. \& Khosla, C. evolution and diversity of assembly-line polyketide synthases. Chem. Rev. 119, 12524-12547 (2019).

4. Asai, T. et al. Structurally diverse chaetophenol productions induced by chemically mediated epigenetic manipulation of fungal gene expression. Org. Lett. 15, 3346-3349 (2013).

5. Asai, T., Yamamoto, T. \& Oshima, Y. Aromatic polyketide production in cordyceps indigotica, an entomopathogenic fungus, Induced by exposure to a histone deacetylase inhibitor. Org. Lett. 14, 2006-2009 (2012).

6. Obata, T. et al. Gold-catalyzed domino synthesis of functionalized benzofurans and tetracyclic isochromans via formal carboalkoxylation. Org. Lett. 18, 4136-4139 (2016).

7. Amouri, H. \& Le Bras, J. Taming reactive phenol tautomers and o-quinone methides with transition metals: a structure-reactivity relationship. Acc. Chem. Res. 35, 501-510 (2002).

8. Ferreira, S. B., da Silva, Fd. C., Pinto, A. C., Gonzaga, D. T. G. \& Ferreira, V. F. Syntheses of chromenes and chromanes via o-quinone methide intermediates. J. Hetero Chem. 46, 1080-1097 (2009).

9. El-Sepelgy, O., Haseloff, S., Alamsetti, S. K. \& Schneider, C. Brønsted acid catalyzed, conjugate addition of beta-dicarbonyls to in situ generated orthoquinone methides enantioselective synthesis of 4-aryl-4H-chromenes. Angew. Chem. Int. Ed. 53, 7923-7927 (2014).

10. Hsiao, C. C., Liao, H. H. \& Rueping, M. Enantio- and diastereoselective access to distant stereocenters embedded within tetrahydroxanthenes: utilizing ortho-quinone methides as reactive intermediates in asymmetric Brønsted acid catalysis. Angew. Chem. Int. Ed. 53, 13258-13263 (2014).

11. Saha, S. \& Schneider, C. Directing group assisted nucleophilic substitution of propargylic alcohols via o-quinone methide intermediates: brønsted acid catalyzed, highly enantio- and diastereoselective synthesis of 7-alkynyl-12aacetamido-substituted benzoxanthenes. Org. Lett. 17, 648-651 (2015).

12. Hsiao, C. C., Raja, S., Liao, H. H., Atodiresei, I. \& Rueping, M. Ortho-quinone methides as reactive intermediates in asymmetric Brønsted acid catalyzed cycloadditions with unactivated alkenes by exclusive activation of the electrophile. Angew. Chem. Int. Ed. 54, 5762-5765 (2015).

13. Lai, Z., Wang, Z. \& Sun, J. Organocatalytic asymmetric nucleophilic addition to o-quinone methides by alcohols. Org. Lett. 17, 6058-6061 (2015).

14. Wang, Z. \& Sun, J. Recent advances in catalytic asymmetric reactions of o-quinone methides. Synthesis 47, 3629-3644 (2015).

15. Zhao, W., Wang, Z., Chu, B. \& Sun, J. Enantioselective formation of all-carbon quaternary stereocenters from indoles and tertiary alcohols bearing a directing group. Angew. Chem. Int. Ed. 54, 1910-1913 (2015).

16. Guo, W. et al. Formal asymmetric catalytic thiolation with a bifunctional catalyst at a water-oil Interface: synthesis of benzyl thiols. Angew. Chem. Int. Ed. 54, 4522-4526 (2015).

17. Alamsetti, S. K., Spanka, M. \& Schneider, C. Synergistic rhodium/phosphoric acid catalysis for the enantioselective addition of oxonium ylides to orthoQquinone methides. Angew. Chem. Int. Ed. 55, 2392-2396 (2016). 
18. Jaworski, A. A. \& Scheidt, K. A. Emerging roles of in situ generated quinone methides in metal-free catalysis. J. Org. Chem. 81, 10145-10153 (2016).

19. Wang, Z. \& Sun, J. Enantioselective [4+2] cycloaddition of o-quinone methides and vinyl sulfides: indirect access to generally substituted chiral chromanes. Org. Lett. 19, 2334-2337 (2017).

20. Wang, Z., Wang, T., Yao, W. \& Lu, Y. Phosphine-catalyzed enantioselective [4 $+2]$ annulation of o-quinone methides with allene ketones. Org. Lett. 19, 4126-4129 (2017).

21. Chen, P. et al. Enantioselective reactions of 2-sulfonylalkyl phenols with allenic esters: dynamic kinetic resolution and [4+2] cycloaddition involving orthoquinone methide intermediates. Angew. Chem. Int. Ed. 56, 3689-3693 (2017).

22. Suneja, A. \& Schneider, C. Phosphoric acid catalyzed [4+1]-cycloannulation reaction of ortho-quinone methides and diazoketones: catalytic, enantioselective access toward cis-2,3-dihydrobenzofurans. Org. Lett. 20, 7576-7580 (2018).

23. Sun, M. et al. Catalytic asymmetric $(4+3)$ cyclizations of in situ generated ortho-quinone methides with 2-indolylmethanols. Angew. Chem. Int. Ed. 58, 8703-8708 (2019).

24. Liu, X., Wang, K., Guo, W., Liu, Y. \& Li, C. An organic-base catalyzed asymmetric 1,4-addition of tritylthiol to in situ generated aza-o-quinone methides at the H2O/DCM interface. Chem. Commun. 55, 2668-2671 (2019).

25. Suneja, A., Loui, H. J. \& Schneider, C. Cooperative catalysis for the highly diastereo- and enantioselective [4+3]-cycloannulation of ortho-quinone methides and carbonyl ylides. Angew. Chem. Int. Ed. 59, 5536-5540 (2020).

26. Lin, X., Liu, Y. \& Li, C. Allylsilane reagent-controlled divergent asymmetric catalytic reactions of 2-naphthoquinone-1-methide. Chem. Eur. J. 26, 14173-14180 (2020).

27. Asai, T. et al. Use of a biosynthetic intermediate to explore the chemical diversity of pseudo-natural fungal polyketides. Nat. Chem. 7, 737-743 (2015).

28. Yang, B. \& Gao, S. Recent advances in the application of Diels-Alder reactions involving o-quinodimethanes, aza-o-quinone methides and o-quinone methides in natural product total synthesis. Chem. Soc. Rev. 47, 7926-7953 (2018).

29. Long, J., Hu, J., Shen, X., Ji, B. \& Ding, K. Discovery of exceptionally efficient catalysts for solvent-free enantioselective hetero-Diels-Alder reaction. J. Am. Chem. Soc. 124, 10-11 (2002).

30. Du, H., Long, J., Hu, J., Li, X. \& Ding, K. 3,3'-Br2-BINOL-Zn complex: a highly efficient catalyst for the enantioselective hetero-Diels-Alder reaction. Org. Lett. 4, 4349-4352 (2002).

31. Du, H. \& Ding, K. Enantioselective catalysis of hetero-Diels-Alder reaction and diethylzinc addition using a single catalyst. Org. Lett. 5, 1091-1093 (2003).

32. Bender, C. F., Yoshimoto, F. K., Paradise, C. L. \& De Brabander, J. K. A concise synthesis of berkelic acid inspired by combining the natural products spicifernin and pulvilloric acid. J. Am. Chem. Soc. 131, 11350-11352 (2009).

33. Takao, K.-i et al. Total synthesis of (+)-Cytosporolide A via a biomimetic hetero-Diels-Alder reaction. J. Am. Chem. Soc. 137, 15971-15977 (2015).

34. Purgett, T. J., Dyer, M. W., Bickel, B., McNeely, J. \& Porco, J. A. Gold(I)mediated cycloisomerization/cycloaddition enables bioinspired syntheses of neonectrolides B-E and analogues. J. Am. Chem. Soc. 141, 15135-15144 (2019).

35. Zi, W. \& Toste, F. D. Recent advances in enantioselective gold catalysis. Chem. Soc. Rev. 45, 4567-4589 (2016).

36. Wu, H., He, Y.-P. \& Gong, L.-Z. Direct access to enantioenriched spiroacetals through asymmetric relay catalytic three-component reaction. Org. Lett. 15, 460-463 (2013).

37. Wang, X. et al. Synthesis of fused bicyclic aminals through sequential gold/ Lewis acid catalysis. Org. Lett. 15, 2234-2237 (2013).

38. Kambale, D. A., Thorat, S. S., Pratapure, M. S., Gonnade, R. G. \& Kontham, R. Lewis acid catalyzed cascade annulation of alkynols with $\alpha$-ketoesters: a facile access to $\gamma$-spiroketal- $\gamma$-lactones. Chem. Comm. 53, 6641-6644 (2017).

39. Wang, C.-S. et al. Metal-catalyzed oxa-[4+2] cyclizations of quinone methides with alkynyl benzyl alcohols. J. Org. Chem. 83, 13861-13873 (2018).

40. Thorat, S. S., Kataria, P. \& Kontham, R. Synthesis of furo[2,3-b]pyran-2-ones through $\mathrm{Ag}(\mathrm{I})$ - or $\mathrm{Ag}(\mathrm{I})-\mathrm{Au}(\mathrm{I})$-catalyzed cascade annulation of alkynols and $\alpha$-ketoesters. Org. Lett. 20, 872-875 (2018).

41. $\mathrm{Hu}, \mathrm{B}$. et al. Asymmetric synthesis of fused bicyclic N,O-and O,O-acetals via cascade reaction by gold(I)/N,N'-dioxide-Nickel(II) bimetallic relay catalysis. Adv. Synth. Catal. 360, 2831-2835 (2018).

42. Zhang, S., Wei, F., Song, C., Jia, J. \& Xu, Z. Recent advances of the combination of Au/acid catalysis. Chin. J. Chem. 32, 937-956 (2014)

43. Wang, X. et al. Synthesis of spiroaminals and spiroketals with bimetallic relay catalysis. Org. Lett. 16, 22-25 (2014).

44. Zhang, S., Xu, Z., Jia, J., Tung, C.-H. \& Xu, Z. Synthesis of spiroaminals by bimetallic $\mathrm{Au} / \mathrm{Sc}$ relay catalysis: TMS as a traceless controlling group. Chem. Comm. 50, 12084-12087 (2014).

45. Wang, B. et al. Gold/Lewis acid catalyzed cycloisomerization/ diastereoselective $[3+2]$ cycloaddition cascade: synthesis of diverse nitrogencontaining spiro heterocycles. Org. Lett. 18, 4614-4617 (2018).

46. Liang, M. et al. Synthesis of spiroketals by synergistic gold and scandium catalysis. Org. Lett. 19, 2526-2529 (2017).
47. Zhang, S. et al. Gold-catalyzed cycloisomerization/1,5-H migration/ Diels-alder reaction cascade: synthesis of complex nitrogen-containing heterocycles. Org. Lett. 19, 1072-1075 (2017).

48. Qi, J., Teng, Q., Thirupathi, N., Tung, C.-H. \& Xu, Z. Diastereoselective synthesis of Polysubstituted spirocyclopenta[c]furans by gold-catalyzed cascade reaction. Org. Lett. 21, 692-695 (2019).

49. Mao, W. et al. Gold-catalyzed domino reactions of alkynol and p-quinone methides: divergent synthesis of fused- and spiro-ketals. Org. Chem. Front. 7, 856-861 (2020).

50. Li, J. et al. Bimetallic gold(I)/chiral N,N'-dioxide Nickel(II) asymmetric relay catalysis: chemo- and enantioselective synthesis of spiroketals and spiroaminals. Angew. Chem. Int. Ed. 55, 6075-6078 (2016).

51. Gong, J., Wan, Q. \& Kang, Q. Gold(I)/chiral Rh(III) Lewis acid relay catalysis enables asymmetric synthesis of spiroketals and spiroaminals. Adv. Syn. Catal. 360, 4031-4036 (2018).

52. Liu, X., Lin, L. \& Feng, X. Chiral N,N'-dioxides: new ligands and organocatalysts for catalytic asymmetric reactions. Acc. Chem. Res. 44, 574-587 (2011).

53. Liu, X., Lin, L. \& Feng, X. Chiral N,N'-dioxide ligands: synthesis, coordination chemistry and asymmetric catalysis. Org. Chem. Front. 1, 298-302 (2014).

54. Liu, X., Zheng, H., Xia, Y., Lin, L. \& Feng, X. Asymmetric cycloaddition and cyclization reactions catalyzed by chiral N,N'-dioxide-metal complexes. Acc. Chem. Res. 50, 2621-2631 (2017).

55. Li, J. et al. Gold(I)/chiral N,N'-dioxide-Nickel(II) relay catalysis for asymmetric tandem intermolecular hydroalkoxylation/Claisen rearrangement. Angew. Chem. Int. Ed. 56, 885-888 (2017).

56. Ge, S. et al. Bimetallic catalytic asymmetric tandem reaction of $\beta$-alkynyl ketones to synthesize 6,6-spiroketals. Angew. Chem. Int. Ed. 58, 4017-4021 (2019).

57. Zheng, H. et al. Diversified 1,6-enynes cycloisomerization/Diels-Alder reactions via bimetallic relay asymmetric catalysis. Angew. Chem. Int. Ed. $\mathbf{5 8}$ 5327-5331 (2019)

58. Ge, S. et al. Bimetallic catalytic tandem reaction of acyclic enynones: enantioselective access to tetrahydrobenzofuran derivatives. Org. Lett. 22, 3551-3556 (2020)

59. Wang, Z., Liu, X. \& Feng, X. Asymmetric catalysis enabled by chiral N,N'Dioxide- Nickel(II) complexes. Aldrichimica ACTA 53, 3-10 (2020).

60. Wang, M. \& Li, W. Feng ligand: privileged chiral ligand in asymmetric catalysis. Chin. J. Chem. 39, 96-984 (2021).

61. Hu, X., Tang, X., Zhang, X., Lin, L. \& Feng, X. Catalytic asymmetric nakamura reaction by Gold(I)/chiral N,N'-dioxide-indium(III) or Nickel(II) synergistic catalysis. Nat. Commun. 12, 3012-3021 (2021).

62. Singleton, D. A. \& Thomas, A. A. High-precision simultaneous determination of multiple small kinetic isotope effects at natural abundance. J. Am. Chem. Soc. 117, 9357-9358 (1995).

63. Bartelson, K. J., Singh, R. P., Foxman, B. M. \& Deng, L. Catalytic asymmetric 4 +2 additions with aliphatic nitroalkenes. Chem. Sci. 2, 1940-1944 (2011).

64. Zhang, D., Lin, L., Yang, J., Liu, X. \& Feng, X. Asymmetric synthesis of tetrahydroindolizines by bimetallic relay catalyzed cycloaddition of pyridinium ylides. Angew. Chem. Int. Ed. 57, 12323-12327 (2018).

\section{Acknowledgements}

We appreciate the National Natural Science Foundation of China $(21871254,21532006$ 21472187) and DICP (DICP ZZBS201602).

\section{Author contributions}

$\mathrm{X}$. Lin. performed experiments and prepared the Supplementary Information and manuscript. X. Liu., K.W., and Q.L. participated some discussions and provided some suggestions. Y. L. and C. L. directed the project and helped with modifying the paper.

\section{Competing interests}

The authors declare no competing interests.

\section{Additional information}

Supplementary information The online version contains supplementary material available at https://doi.org/10.1038/s41467-021-25198-y.

Correspondence and requests for materials should be addressed to Y.L. or C.L.

Peer review information Nature Communications thanks the anonymous reviewer(s) for their contribution to the peer review of this work. Peer reviewer reports are available.

Reprints and permission information is available at http://www.nature.com/reprints

Publisher's note Springer Nature remains neutral with regard to jurisdictional claims in published maps and institutional affiliations. 
(c) (i) Open Access This article is licensed under a Creative Commons Attribution 4.0 International License, which permits use, sharing, adaptation, distribution and reproduction in any medium or format, as long as you give appropriate credit to the original author(s) and the source, provide a link to the Creative Commons license, and indicate if changes were made. The images or other third party material in this article are included in the article's Creative Commons license, unless indicated otherwise in a credit line to the material. If material is not included in the article's Creative Commons license and your intended use is not permitted by statutory regulation or exceeds the permitted use, you will need to obtain permission directly from the copyright holder. To view a copy of this license, visit http://creativecommons.org/ licenses/by/4.0/.

(C) The Author(s) 2021 